\title{
A força
do varejo
}

bserva-se uma tendência mundial de concentração no setor varejista. Como conseqüência, aumenta seu poder de negociação com fornecedores eestreitam-se seus laços com os clientes. Em contrapartida, a indústria tenta adaptar-se na expectativa de defender margens de negociação de preços, aumentar a distribuição de seus produtos e criar novas formas de relacionamento com 0 consumidor final. 0 artigo analisa a situação do varejo no país e no mundo, explora sua relação com a indústria e oferece estimativas dos impactos sobre os consumidores.

\section{por Adriana Winer FGVEAESP}

Ao que tudo indica, o varejo está entrando em uma nova onda de concentração no Brasil. Após passarem os últimos anos digerindo aquisições do passado e buscando ganhos de eficiência, as empresas líderes voltam a crescer. Evento emblemático foi a compra da rede Sonae pelo gigante norte-americano Wal-Mart, no final de 2005, por US\$760 milhões. Com a aquisição do quarto colocado no ranking, o Wal-Mart aumentou suas vendas de R \$ 6,1 bilhões para previstos R $\$ 11$ bilhões em 2005, o que o coloca próximo ao Carrefour, o segundo colocado, com $\mathrm{R} \$ 13$ bilhões de faturamento. Em primeiro lugar, continua o Pão de Açúcar, com vendas de R\$15,4 bilhões em 2004. 
Para se ter uma idéia da concentração, esses três primeiros colocados ficam muito distantes do quarto, a rede gaúcha Zaffari, com faturamento de R \$ 1,26 bilhão em 2004. Em números, a participação no faturamento do setor representado pelo Pão de Açúcar, Carrefour e WalMart subiu de $34,4 \%$ para $38,8 \%$ - um aumento de $12,8 \%$.

Tendência de concentração. Essa concentração pode ser observada nas estratégias de crescimento adotadas pela rede Wal-Mart no Brasil. Além de ganhar musculatura no Sul, onde o português Sonae dominava, o Wal-Mart é potente no Nordeste, desde que, em 2004, adquiriu a rede Bompreço, do grupo holandês Royal Ahold, por US $\$ 300$ milhões. A rede ficou com 295 lojas em 17 estados. Em 2006, o Wal-Mart declarou que pretende ainda investir R\$ 600 milhões nas regiões N ordeste e Sudeste e abrir nelas mais 15 lojas. de acordo com estimativa de Nirmalya Kumar, professor da London Business School, no artigo intitulado "The Global Retail Challenge", publicado em 2005 na Business Srategy Review.

N ão há dúvida de que aumenta o poder de negociação do varejo com seus fornecedores, como vêm mostrando reportagens e estudos nos últimos anos. Surgem, entretanto, implicações não tão óbvias. A indústria está à altura do desafio? 0 consumidor sai ganhando ou perdendo? São questões polêmicas, sem uma resposta ainda clara, dado o poder de argumentação dos diferentes interesses envolvidos. $\mathrm{Na}$ discussão a seguir, o objetivo é providenciar argumentos que ajudem o leitor a tirar suas conclusões sobre essas questões.

O segredo dos preços. A principal pressão do varejo internacionalizado, segundo Kumar, é para que os fornecedores uniformizem suas práticas de preço globais. Por alegadas questões de competitividade ou custo local, as multinacionais fabricam bens de consumo similares com preços que podem variar até $60 \%$ entre países. Essa diferença não é mais aceita pelas redes de varejo, cada vez mais cientes da realidade. Um exemplo: ao comprar a polonesa $\mathrm{Hit}$, a inglesa Tesco descobriu que a pequena rede conseguia preços melhores do que ela própria,

Se o Wal-Mart modificará o cenário brasileiro como fez em seu país de origem, os Estados Unidos, ou se suas estratégias não vão levar ao efeito desejado, como ocorreu com o Sonae, que havia investido US\$ 1 bilhão no Brasil e regressou a Portugal, só o tempo dirá. N em todas as aquisições de grupos globais pelo mundo vêm dando certo, mas um fato não pode ser ignorado: a crescente internacionalização e a concentração do varejo. As redes se globalizam, fazem compras centrais e diversificam os formatos de lojas, o portfólio de produtos, canais e negócios.

Os cinco líderes do ranking mundial respondem atualmente por $32 \%$ das vendas feitas pela indústria no planeta, contra os $21 \%$ de cinco anos atrás. E a expectativa é de que nos próximos cinco anos o percentual suba para $45 \%$, terceira potência de varejo do mundo.

Com a pressão por preços uniformes, a indústria está sendo obrigada a mudar a forma de se organizar. Divisões por produto ou por país dão lugar a divisões por consumidor ou por relacionamento. Atender o cliente de varejo globalmente e coordenar as ações em todos os países é 0 desafio do momento, acredita o professor da London School. Não parece uma tarefa fácil, até porque nem sempre essa padronização de preços é transparente e possível. Um estudo da consultoria Bain revela que apenas $24 \%$ de um total de 38 grandes fornecedores da Wal-M art obtêm lucratividade acima da média.

No Brasil, a situação não é diferente. A indústria se queixa de práticas comerciais que achatam suas margens 
na negociação das condições de entrega, armazenamento, colocação nas gôndolas e participação em campanhas publicitárias. Ao inaugurar uma nova loja, por exemplo, a rede "pede" aos fornecedores que o primeiro lote de produtos seja gratuito - prática conhecida como "enxoval". Ajudar na decoração no mês de aniversário e custear reformas em setores específicos são outras exigências comuns - sem contar taxas de cadastramento de produtos, por posição privilegiada nas prateleiras e para inclusão em encartes, entre outras.

Estudo feito pela GVConsult, a pedido da Federação das Indústrias do Estado de São Paulo (Fiesp), em 2004, revelou 27 cláusulas semel hantes às citadas acima. Foram consideradas cláusulas não-concorrenciais pelos autores do estudo, pois poderiam estar sendo utilizadas para discriminar fornecedores, criar dificuldades de funcionamento para as empresas e limitar ou impedir o acesso de novos concorrentes ao mercado, entre outros aspectos. As "condições especiais" não teriam como contrapartida um aumento de eficiência e competitividade dos lojistas. Além disso, a redução dos preços ao consumidor não podia ser comprovada, sendo mais forte em al guns segmentos, como o de alimentos. 0 poder dos varejistas também gerou CPIS por todo o Brasil, instauradas para apurar as relações comerciais entre as grandes redes e a indústria.

Para coibir práticas abusivas, códigos de conduta foram adotados em países como a Inglaterra. No Brasil, ainda não há qualquer restrição. Adicional mente, tudo indica que o poder dos maiores vai crescer. Recentes parcerias com bancos privados permitem que estes fortaleçam suas relações com as classes mais baixas e liberam as redes da preocupação com 0 financiamento, deixando-as livres para usar seu caixa em novas aquisições.

0 Pão de Açúcar e o Itaú formaram recentemente a financeira FIC. Na conta da rede entraram $\mathrm{R} \$ 380$ milhões, valor que o Itaú pagou pelo direito de explorar os pontos. Hoje, com o controle da rede compartilhado com o grupo francês Casino, a empresa planeja investir US\$ 1 bilhão nos próximos quatro anos e abrir 160 novas lojas até 2010.
Marcas próprias. 0 varejo também ganha espaço para negociação ao construir suas próprias marcas. Aprimorase em escala, domínio de mercado e informação sobre os consumidores, o que confere aos que se destacam diferenciais em relação à concorrência. No Brasil, as marcas próprias saltaram de 38 mil em 2004 para 43 mil em 2005, um acréscimo de 13\%. Segundo a ACN ielsen, 0 percentual de conhecimento das marcas próprias junto aos consumidores cresceu 10\% de 2004 para 2005, e 91\% das pessoas que utilizam esses produtos os recomendam para outras pessoas.

0 preço é determinante - custam entre 10\% a 40\% menos do que produtos similares. 0 Wal-Mart possui 17 marcas próprias, que abrigam 6,4 mil itens, e planeja adicionar, todos os anos, de 500 a 600 novos produtos. No Pão de Açúcar, a linha GoodLight, primeira marca própria exclusiva no segmento light da América Latina, éuma das campeãs de venda, mesmo com preço acima das concorrentes.

No Brasil, ainda há um bom potencial para o crescimento das marcas próprias, que respondem por pouco mais de $5 \%$ do faturamento das grandes redes - um percentual bem inferior ao de mercados amadurecidos. $\mathrm{Na}$ rede suíça Migros, $85 \%$ dos produtos nas gôndolas levam sua assinatura. No Reino Unido, representam $41 \%$

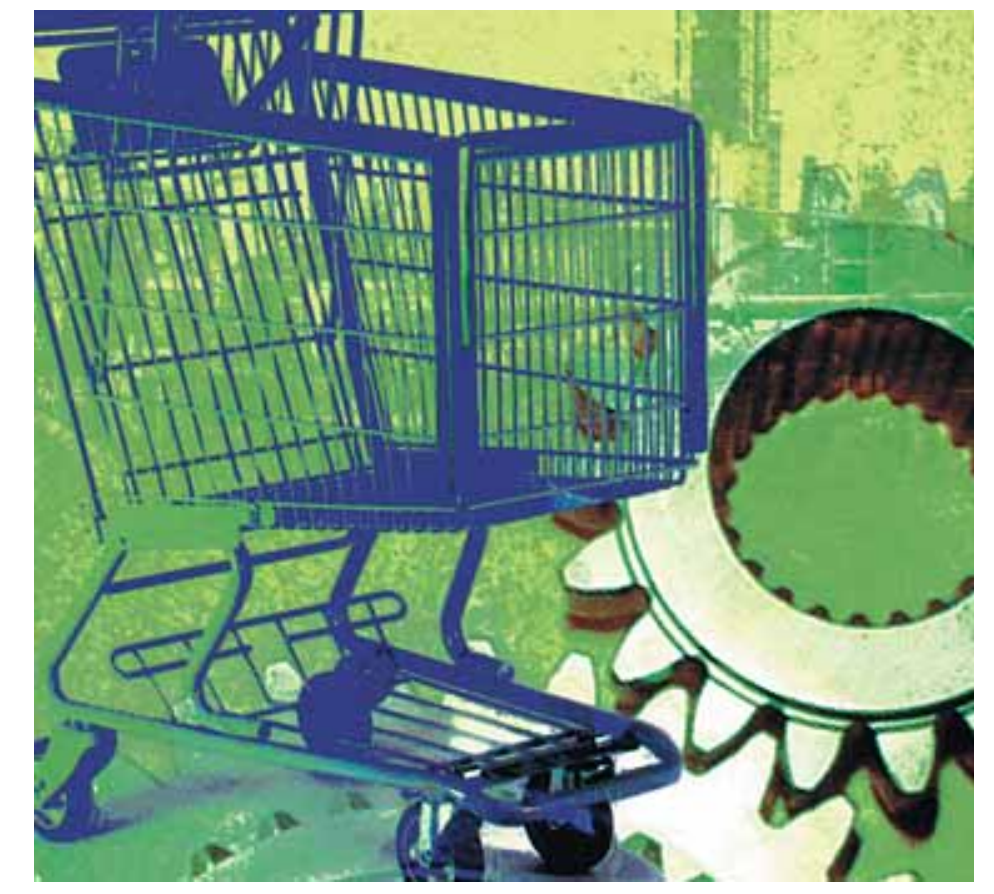


do mercado. N os Estados Unidos, um em cada cinco itens vendidos em supermercados e drogarias é de marca própria. Algumas redes, como Safeway, dona de uma linha com 2.500 itens standard e 1.100 premium, operam com suas próprias fábricas.

Com a expansão das marcas próprias, as redes tornam-se responsáveis pela qualidade dos produtos. Para garantir a origem, principalmente quando se trata de alimentos, 30 grandes varejistas globais com presença na Europa, como Tesco, Ahold e McDonald's, resolveram formar o EurepGap, uma organização sem fins lucrativos que busca uma convergência para normas de certificação de alimentos exportados ao mercado europeu. Sua ambição é não só ficar restrita à Europa, e sim construir padrões globais para o comércio exterior.
Mart, a maior rede do mundo? Aparentemente, muitas. Mesmo sendo mais da metade do tamanho do segundo colocado, o Carrefour, mesmo se considerando que oito em cada dez americanos compram no Wal-M art ao menos uma vez por ano, a empresa representa apenas $8 \%$ do total das vendas no varejo nos Estados Unidos. Não é incomum, para empresas em mercados maduros, comandar participações de mercado superiores a 30\%.

No entanto, seu tamanho assusta comunidades dentro e fora dos Estados Unidos e, às vezes, a obriga a ser menos ousada do que gostaria. Na Califórnia, há uma resistência à abertura de novas Iojas. Processos contra práticas trabalhistas e investigação a respeito de boicote à sindical ização ganham manchetes de jornais.

Em sua expansão internacional, a empresa também enfrenta obstáculos. Não houve qualquer problema no México, Canadá e Inglaterra, mas sofre, por exemplo, no Japão, onde preço baixo é sinônimo de baixa qualidade. $\mathrm{Na}$ Alemanha, teve dificuldades ao competir com redes ainda mais agressivas, como a Aldi. 0 modelo padronizado, sempre uma vantagem competitiva da rede, talvez tenha que ser administrado de forma diversa no exterior, dada a complexidade de formatos de lojas e gostos dos consumidores.

As "boas práticas" do EurepGap vêm sendo seguidas por 35 mil propriedades em 1 milhão de hectares espaIhados por 62 países. O s sócios da O NG dizem que não se trata de uma obrigação, e sim de preferência a fornecedores certificados. Obviamente, ser o primeiro da fila faz toda a diferença. No sistema de acompanhamento do EurepGap, a movimentação do produto fica registrada, desde que foi recebido, processado e embalado, até a distribuição. E a tendência é que as informações fiquem disponíveis aos consumidores.

Os limites do varejo. Se tantos aspectos mostram a força do varejo, outros servem para relativizar sua onipotência. Quais são as possibilidades de crescimento do Wal-
O Wal-Mart ganha em preço e talvez na seleção, mas dois terços dos consumidores acreditam que a rede venda produtos de média qualidade e serviços limitados que não compensam a economia. Ou seja, há consumidores de ol ho em alternativas, segundo estudo publicado por consultores da Bain, na Harvard Business Review. Muitas redes conseguem explorar as fraquezas e coexistir com o Wal-M art, como é o caso da Walgreens, em farmácia, e da Best Buy, em el etrônicos.

No caso do Carrefour, surgem desafios em casa e no exterior. 0 Carrefour, a rede mais internacionalizada, nunca havia saído de um país, com a exceção do Chile, em 2003. Mas em 2005 desistiu de operar no difícil mercado japonês e vendeu 29 hipermercados no M éxico, onde não 
conseguiu competir com o Walmex. Também fez uma troca de seus hipermercados na República Checa e Eslováquia pelas Iojas do Tesco, em Taiwan. Não quer dizer que seus negócios no exterior não estão dando certo. A rede expandiu suas operações na Polônia, Brasil, Itália, Turquia, China, Indonésia, Coréia do Sul e Colômbia. Na França, onde gera metade de vendas e lucros, o Carrefour enfrenta problemas. Perdeu sua reputação de preços baixos, trocou de presidente e a integração com a rede Promodes nunca foi bem absorvida.

Buscando brechas. De seu lado, a indústria procura ganhar forças. Muitos interpretaram a compra da Gillette pela Procter \& Gamble como uma reação ao poder do varejo. Além de concentrar ativos, empresas como a $P \& G$ vêm racionalizando sua estrutura e focando em produtos líderes. A Unilever está finalizando seu plano de reduzir o número de marcas de 1.600 para 400 . N estlé e Unilever fecharam mais de uma centena de fábricas. As multinacionais de bens de consumo, a exemplo dos varejistas, passaram a fazer compras globais de matériaprima a preços favoráveis.

No Brasil, a indústria tem procurado estreitar seu relacionamento com os pequenos varejistas. As grandes redes reclamam de fornecedores que estariam dando condições desiguais para os pequenos da periferia e para o atacado e que já teriam inviabilizado clientes maiores.

Alguns grupos industriais de bens de consumo tentaram vender direto ao varejo, integraram os sistemas, meIhoraram a logística e ajudaram no investimento de gestão por categorias. Os pequenos ainda se associaram para reduzir custos de marketing, transporte e fortalecer as condições de negociação.

Mas as multinacionais chegaram à conclusão de que o investimento não compensava, pois o custo se revelou muito alto. Voltaram a atuar com as redes de atacado, que atinge até 900 mil pontos-de-venda. Na negociação com fabricantes, 0 atacado chega a ter, em média, preços $6 \%$ a $8 \%$ inferiores aos cobrados pela indústria ao grande varejo.

0 pequeno varejo cresceu nos últimos anos, de acordo com a ACNielsen. Somente na Grande São Paulo sua participação caiu, dada a maior concentração. Expandiuse principalmente no Nordeste, Minas Gerais, Espírito
Santo e interior do Rio de Janeiro. A parcela de mercado das lojas de formato de até 250 metros quadrados subiu de $19,3 \%$ em 2002 para 32,4\% em 2004. Os supermercados grandes e médios perderam espaço.

Proximidade, variedade de produtos e bom atendimento passaram a contar, mas preço ainda é determinante. $\mathrm{N}$ a seção mercearia sal gada, a $\mathrm{ACN}$ ielsen constatou que $42 \%$ dos produtos das marcas líderes tinham preços menores praticados no pequeno varejo do que nas lojas maiores, percentual que subia para $52 \%$ na mercearia doce e $69,5 \%$ no setor de higiene pessoal. Vale uma ressalva: pequeno varejo, para a ACNielsen, não é sinônimo de pequenas empresas, e sim de lojas compactas. Os líderes de mercado estão atentos à tendência e investem no formato predileto de comércio.

0 poder da Internet deve ser levado em conta no balanço de forças. A Forrester prevê que o comércio eletrônico deve ter superado 100 bilhões de dólares em vendas no ano de 2005 e dobrará este valor até 2010, quando mais da metade dos computadores, um quarto dos cosméticos e mais de $10 \%$ das roupas serão vendidos on-line nos Estados Unidos. Os varejistas podem montar lojas virtuais ainda maiores do que as de tijolo, mas o comércio eletrônico também fornece possibilidades de a indústria se relacionar diretamente com o consumidor. Afinal, ela já vem adotando essa estratégia via canais de serviços diretos. A Danone abastece com suas fontes de água 1,7 milhão de lares e empresas nos Estados Unidos. Multinacionais do consumo vendem cada vez mais produtos em máquinas automáticas.

Recomenda-se, portanto, cautela a quem acredite que a vitória do varejo é inevitável. As suas forças crescem de fato, mas há dúvidas e brechas no horizonte. Quanto ao consumidor, está mais perto das redes de comércio do que da indústria. Preços menores e mais informações contam a seu favor, mas vale levar em consideração o alerta de estudos que levantam os custos da concentração e a fal ta de transparência no repasse das condições de negociação ao elo final da cadeia.

\section{AdrianaWliner}

Jornalista e Doutoranda em Administração na FGV-EAESP

E-mail: wilner@uol.com.br 